\title{
A telephone survey of factors affecting willingness to participate in health research surveys
}

DC Glass ${ }^{1 *}$, HL Kelsall', C. Slegers ${ }^{1}$, AB Forbes ${ }^{1}$, B. Loff', D. Zion² and L. Fritschi ${ }^{3}$

\begin{abstract}
Background: In recent years, reduced participation has been encountered across all epidemiological study designs, both in terms of non-response as well as refusal. A low response rate may reduce the statistical power but, more importantly, results may not be generalizable to the wider community.

Methods: In a telephone survey of 1413 randomly selected members of the Australian general population and of 690 participants sourced from previous studies, we examined factors affecting people's stated willingness to participate in health research.

Results: The majority of participants (61\%) expressed willingness to participate in health research in general but the percentage increased when provided with more specific information about the research. People were more willing if they have personal experience of the disease under study, and if the study was funded by government or charity rather than pharmaceutical companies.

Participants from previous studies, older people and women were the groups most willing to participate. Younger men preferred online surveys, older people a written questionnaire, and few participants in any age and sex groups preferred a telephone questionnaire.

Conclusion: Despite a trend toward reduced participation rates, most participants expressed their willingness to participate in health research. However, when seeking participants, researchers should be concrete and specific about the nature of the research they want to carry out. The preferred method of recommended contact varies with the demographic characteristics.
\end{abstract}

Keywords: Epidemiology, Population studies

\section{Background}

In recent years, reduced participation has been encountered across all epidemiological study designs [1]. Fewer potential participants are contactable [2], and a reduced proportion of those contacted respond to invitations [3-5] sometimes because the potential responder did not receive or did not take notice of the invitation [6]. There is also less likelihood that those contacted will participate; the refusal rate for telephone surveys has gone from $4 \%$ in the 1950 s and 60 s to $53 \%$ in 1990 [2]. In consumer surveys,

\footnotetext{
*Correspondence: deborah.glass@monash.edu

'Department of Epidemiology and Preventive Medicine, Monash University, The Alfred Centre, 99 Commercial Rd, Melbourne 3004, VIC, Australia
} Full list of author information is available at the end of the article the decline in telephone response rates increased between 1996 and 2003 [7].

Nonresponses and failure to make contact with possible participants based on a predetermined number of contact attempts stated in the study protocol, are a problem in epidemiology because they may result in smaller sample sizes and reduced power. More importantly however, the results from low response rates may not be generalizable to the wider community because the survey respondents may differ in important ways from the general population and so are not representative [2, 3, 8-12].

In this study we sought to understand how willing people are to participate in health research and investigate the factors that affect their willingness to

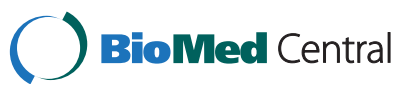

(c) 2015 Glass et al. Open Access This article is distributed under the terms of the Creative Commons Attribution 4.0 International License (http://creativecommons.org/licenses/by/4.0/), which permits unrestricted use, distribution, and reproduction in any medium, provided you give appropriate credit to the original author(s) and the source, provide a link to the Creative Commons license, and indicate if changes were made. The Creative Commons Public Domain Dedication waiver (http://creativecommons.org/publicdomain/zero/1.0/) applies to the data made available in this article, unless otherwise stated. 
participate. To this end, we organised a telephone survey of a random sample of Australians to identify their willingness to take part in heath research.

We also undertook the telephone survey in a sample of participants from an existing cohort and a previous case-control study to identify the willingness of known study participants to take part in another health study and to identify differences in their views compared to those who had not previously participated in such a study eg on the role of Ethics Committees [13].

\section{Methods}

\section{Participants}

In order establish willingness of the general Australian population to participate in health surveys we chose a random sample of the Australian population. We also solicited views from individuals who had previously taken part in health surveys to identify whether this had led to a change in willingness to participate.

The study population had three groups:

1. The general population.

2. Previous participants from a case-control study

3. Previous participants from a cohort study

To obtain the general population sample, a sample of 7000 randomly generated working telephone numbers was obtained from a commercial list provider. Of these, a geographically representative sample of 4000 landline telephone numbers were drawn from the capital city and nonmetropolitan area of each state and territory in proportion to their population. In addition, 3000 mobile telephone numbers were drawn to ensure that we had adequate representation of individuals with mobile telephones who may not have landlines. In order to randomise the choice of the individual who was surveyed within each household, the interviewer asked to speak to the household member who was aged over 18 years and who had the next birthday.

For the cohort, a random sample of 600 individuals who were under 80 years, living in Australia and for whom a telephone number was available was drawn from an existing prospective occupational cohort. [14] (Table 1). The cohort was a cancer and mortality study of approximately 18,000 workers in the Australian petroleum industry of whom $90 \%$ were male [15]. Employees had been enrolled in the cohort by participating in face to face interviews in at least one of four surveys between 1980 and 2000 which took place during work time with help from the site medical services. Over $90 \%$ of eligible employees participated in the cohort. Refusal to participate was uncommon. The major cause of nonparticipation was difficulty in locating individuals because of temporary absences such as sick leave or annual leave [15].

The case-control study of bowel cancer in Western Australia recruited 918 cases diagnosed between 2005 and 2007 and controls selected from the Western Australian electoral roll [16].(National Electoral roll registration is compulsory for everyone 18 years and over.) The patients in WABOHS were men and women aged between 40 and 79 [17]. Participants had been asked if they would be prepared to take part in other related research and we invited a random sample of 200 participants from those who had agreed to do so (Table 1).

\section{Data collection}

Introductory letters explaining the study were sent to members of the three samples for whom an address could be identified. Addresses were not available for those with mobile telephone numbers. The letter was followed by a telephone call by a trained interviewer inviting the potential participant to complete a computer-assisted telephone

Table 1 Study population and participation rates by study sample groups

\begin{tabular}{|c|c|c|c|c|c|c|c|}
\hline & \multicolumn{7}{|c|}{ Complete study population } \\
\hline & \multicolumn{4}{|c|}{ General population sample } & \multirow{3}{*}{$\begin{array}{l}\text { Case-control } \\
\text { study } \\
\text { Letter sent }\end{array}$} & \multirow{3}{*}{$\begin{array}{l}\text { Cohort } \\
\text { study } \\
\text { Letter sent }\end{array}$} & \multirow{3}{*}{$\begin{array}{l}\text { Total study } \\
\text { population }\end{array}$} \\
\hline & \multicolumn{3}{|l|}{ Landline } & \multirow{2}{*}{$\begin{array}{l}\text { Mobile telephone } \\
\text { No letter }\end{array}$} & & & \\
\hline & Letter sent & No letter & All landline & & & & \\
\hline Study population approached $n$ & 1806 & 2194 & 4000 & 3000 & 200 & 600 & 7800 \\
\hline Non-contact/phone number unusable ${ }^{a} n$ & 391 & 1123 & 1514 & 2005 & 33 & 77 & 3629 \\
\hline Eligible population ${ }^{b} n$ & 1415 & 1071 & 2486 & 995 & 167 & 523 & 4171 \\
\hline Refusalsc & 761 & 631 & 1372 & 540 & 14 & 122 & 2068 \\
\hline Completed interviews $n$ & 654 & 440 & 1094 & 455 & 153 & 401 & 2103 \\
\hline Participation rate \% & 46.2 & 41.1 & 44.0 & 45.7 & 91.6 & 76.7 & 50.4 \\
\hline
\end{tabular}

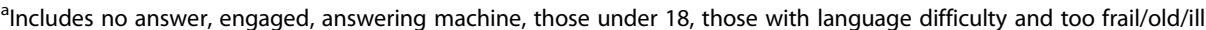

${ }^{b}$ Excludes non-contacts

Includes those who actively declined or claimed to have already done the survey, or made but did not keep an appointment, or terminated during the survey, or said that they did not know the named person or who asked to be removed from the list 
interview (CATI). Where no address was available the potential participant was called without a prior introductory letter. Up to ten phone call attempts to contact the potential participant were made at different times of day and days of the week. Participation was voluntary and interviews could be terminated at any time.

An initial questionnaire was drafted based on that used in a previous Canadian study [18] and it was modified following qualitative research that we conducted in order to identify questions of relevance to Australian participation in health research [19].

Our questionnaire commenced with an initial general question about willingness to participate in health research and there were 12 follow-up questions seeking to identify factors that affected willingness. These included the reason for the research e.g., treatment or prevention of disease or planning hospital services; whether the disease was one they or a close friend or relative had experienced; the funding source for the research e.g., charity, government or pharmaceutical industry; and how the individual had been selected to take part in the study e.g., randomly selected or from their General Practitioner (GP). Participants were also asked whether receipt of a summary of the research results would make them more willing to take part. All responses were scored from 1 to 5. One was Very Unwilling, two was Unwilling, three was Neutral, four was Willing and five was Very Willing to participate. Participants were then asked whether, if they were to take part in research, they would prefer shorter or longer explanatory statements about the research and whether they would prefer a telephone survey, postal survey or an online survey.

We asked for demographic details (age, sex, highest level of formal education, postal area code of residential address, Aboriginal and Torres Strait Islander (ATSI) status, and country of birth), whether they had a long term disease or disability and their previous participation in health research.

Postal area code data were used to assign the Socio-Economic Indexes for Areas (SEIFA), an aggregate index of relative socio-economic disadvantage [20] and to group individuals by remoteness [21]. National comparison data were drawn from Australian Bureau of Statistics (ABS) data released in 2008 for education [22] and in 2012 for sex, age and ATSI status [23, 24].

Analysis was carried out using Stata version 11.2 [25]. For questions about willingness to participate, Very Unwilling and Unwilling responses were grouped together, as were Very Willing and Willing. This resulted in a three level ordinal outcome variable of willingness to participate. Assessment of associations between candidate binary predictor variables and the ordered outcome variable was performed with chi-squared tests for trend, and ordinal logistic regression was used for the ordered predictor variables (age, remoteness and SEIFA). Assessment of other associations between non-ordered categorical variables was performed using conventional chi-squared tests.

A multivariable analysis of predictors of being willing or very willing to participate was performed using logistic regression for each participant group separately.

Ethics Committee approval was granted by Monash University Human Research Ethics Committee (HREC), by University of Western Australia Ethics Committee in respect of the Case-control study and by relevant Ethics Committees for the Aboriginal and Torres Strait Islander focus groups.

\section{Results}

After excluding individuals who could not be contacted, there were a total of 4171 eligible participants of whom 2103 (50.4 \%) participated. The participation fraction was $44.5 \%$ for the general population sample and over $80 \%$ for those who had participated in previous epidemiological studies. (Table 1) There was no significant difference in the participation fraction between people who we contacted using their mobile number and landline number $(p=0.85)$. For the general population sample with a landline, the response was $5 \%$ greater in those for whom we had an address, and sent a letter, than for those for whom we did not have an address and did not send an introductory letter prior to contacting them.

Table 2 shows that in comparison with the Australian general population, our general population sample had a greater proportion of women than men (58 vs $51 \%$ ), were more likely to come from outer regional, remote or very remote areas (21 vs $12 \%$ ), had a higher level of tertiary education ( 35 vs $24 \%$ ) and were more likely to be in the most socio-economically advantaged quintile ( 25 vs $20 \%$ ). Three quarters of the general population sample had not previously participated in a health survey and a similar proportion did not have a long-term disease or disability. Only $1 \%$ in each of the three study groups spontaneously raised questions about privacy.

Most of the case-control study respondents were over 60 years of age and $60 \%$ were male (Table 2). Consistent with the composition of the cohort, most ( $94 \%$ ) of the cohort respondents were male and the majority were over 60 years of age.

Nearly two-thirds $(61 \%)$ of the general population sample stated that they would be willing or very willing to participate in health surveys and only $11 \%$ said that they were generally unwilling (Table 3 ). A higher proportion, $83 \%$, of the participants drawn from the cohort and case control study were willing to participate in another study. 
Table 2 Demographic characteristics of participants

\begin{tabular}{|c|c|c|c|c|c|}
\hline & & $\begin{array}{l}\text { Australian population \% } \\
\text { (ABS data) }[20-24]\end{array}$ & $\begin{array}{l}\text { General population } \\
\text { sample } \% n=1559\end{array}$ & $\begin{array}{l}\text { Case-control study } \\
\text { sample } \% n=153\end{array}$ & $\begin{array}{l}\text { Cohort study } \\
\text { sample } \% n=401\end{array}$ \\
\hline & & \multicolumn{4}{|l|}{ Aged $\geq 18$} \\
\hline \multicolumn{2}{|l|}{ Male $^{a}$} & 49 & 42 & 61 & 94 \\
\hline \multicolumn{2}{|l|}{ Female } & 51 & 58 & 39 & 6 \\
\hline \multicolumn{2}{|l|}{ Age $^{a} \quad 18-39$ years } & 40 & 28 & 0 & 1 \\
\hline \multicolumn{2}{|l|}{$40-60$ years } & 34 & 41 & 13 & 39 \\
\hline \multicolumn{2}{|l|}{$>60$ years } & 26 & 31 & 87 & 60 \\
\hline \multicolumn{2}{|l|}{ ATSI: ${ }^{a b}$ Yes } & 2.5 & 1 & 2 & 1 \\
\hline \multicolumn{2}{|l|}{ No } & 97.5 & 99 & 98 & 99 \\
\hline \multicolumn{6}{|l|}{ Country of birth ${ }^{a}$} \\
\hline \multicolumn{2}{|l|}{ Australia } & 73 & 77 & 70 & 75 \\
\hline \multicolumn{2}{|l|}{ Other } & 27 & 23 & 30 & 25 \\
\hline \multicolumn{2}{|l|}{ Highest level of education ${ }^{a}$} & $25-64$ years only & & & \\
\hline \multicolumn{2}{|l|}{ School } & 41 & 42 & 49 & 46 \\
\hline \multicolumn{2}{|l|}{ Technical/trade certificate } & 35 & 22 & 30 & 32 \\
\hline \multicolumn{2}{|l|}{ Tertiary } & 24 & 35 & 21 & 22 \\
\hline \multicolumn{2}{|l|}{ Other } & - & 1 & 0 & 0 \\
\hline \multicolumn{6}{|l|}{ Remoteness index ${ }^{a}$} \\
\hline \multicolumn{2}{|l|}{ Metropolitan } & 69 & 56 & 61 & 68 \\
\hline \multicolumn{2}{|l|}{ Inner regional } & 20 & 22 & 28 & 24 \\
\hline \multicolumn{2}{|l|}{ Outer regional/Remote } & 12 & 21 & 10 & 8 \\
\hline \multicolumn{6}{|l|}{ SEIFA Relative Disadvantage ${ }^{a c}$} \\
\hline \multicolumn{2}{|l|}{ Quintile 1 least advantaged } & 20 & 14 & 2 & 10 \\
\hline \multicolumn{2}{|l|}{ Quintile 2} & 20 & 20 & 13 & 18 \\
\hline \multicolumn{2}{|l|}{ Quintile 3} & 20 & 22 & 27 & 18 \\
\hline \multicolumn{2}{|l|}{ Quintile 4} & 20 & 19 & 22 & 24 \\
\hline \multicolumn{2}{|l|}{ Quintile 5 most advantaged } & 20 & 25 & 36 & 30 \\
\hline \multirow[t]{2}{*}{ Previously done health survey } & Yes & & 26 & 100 & 100 \\
\hline & No & & 74 & 0 & 0 \\
\hline \multirow[t]{2}{*}{ Previously refused health survey } & Yes & & 11 & 8 & 10 \\
\hline & No refusal & & 89 & 92 & 90 \\
\hline \multirow[t]{2}{*}{ Long-term disease/disability } & Yes & & 25 & 43 & 30 \\
\hline & No & & 75 & 56 & 71 \\
\hline
\end{tabular}

${ }^{a}$ Chi squared test $p<0.05$ of comparison between the Australian population (column 2) and the general population sample (column3)

${ }^{b}$ Aboriginal or Torres Strait Islander

'SEIFA, Socio-Economic Indexes for Areas is an aggregate score of relative socio-economic disadvantage; the lower the score the higher the relative disadvantage

For the general population sample, greater willingness to participate was reported by women than men (61 vs $58 \% p=0.047)$, older than younger people, and those with a long term disease or disability. There was no significant difference in initial willingness to participate by country of birth, level of education or remoteness (Table 3). In the general population sample, the lowest stated willingness by age and sex was $46 \%$, for men under the age of 40 , the highest was $72 \%$, for men over
60. Previous participation or not having previously refused to participate in a health survey was also a strong predictor of willingness to participate.

Similar results in terms of willingness to participate by most demographic characteristics were seen for the case-control and cohort participants (Table 3). For both groups of previous health survey participants however, long term disease or disability did not increase their willingness to participate. The previous cohort participants 
Table 3 Stated willingness to participate in health studies by demographic characteristics

\begin{tabular}{|c|c|c|c|c|c|c|c|c|c|c|c|c|c|c|c|}
\hline & \multicolumn{5}{|c|}{ General population row \% } & \multicolumn{5}{|c|}{ Case-control study participants row \% } & \multicolumn{5}{|c|}{ Cohort study participants row \% } \\
\hline & Number & $\begin{array}{l}\text { Very unwilling/ } \\
\text { Unwilling }\end{array}$ & Neutral & $\begin{array}{l}\text { Very willing/ } \\
\text { Willing }\end{array}$ & $p$ value $^{a}$ & Number & $\begin{array}{l}\text { Very unwilling/ } \\
\text { Unwilling }\end{array}$ & Neutral & $\begin{array}{l}\text { Very } \\
\text { willing/ } \\
\text { Willing }\end{array}$ & $p$ value $^{a}$ & Number & $\begin{array}{l}\text { Very unwilling/ } \\
\text { Unwilling }\end{array}$ & Neutral & $\begin{array}{l}\text { Very willing/ } \\
\text { Willing }\end{array}$ & $p$ value $^{a}$ \\
\hline Whole group & 1546 & 11 & 28 & 61 & & 153 & 1 & 5 & 93 & & 401 & 13 & 69 & 319 & \\
\hline Male & 653 & 12 & 30 & 58 & 0.047 & 93 & 2 & 2 & 96 & 0.182 & 375 & 3 & 65 & 297 & 0.469 \\
\hline Female & 893 & 10 & 27 & 61 & & 60 & 0 & 10 & 90 & & 26 & 0 & 4 & 22 & \\
\hline Age $<40$ years & 428 & 12 & 36 & 52 & $<0.001$ & 0 & 0 & 0 & 0 & 0.992 & 3 & 0 & 67 & 33 & 0.056 \\
\hline $40-60$ years & 637 & 11 & 29 & 60 & & 20 & 0 & 0 & 100 & & 156 & 3 & 21 & 76 & \\
\hline$>60$ years & 475 & 10 & 20 & 70 & & 132 & 2 & 6 & 92 & & 241 & 3 & 14 & 83 & \\
\hline ATSI ${ }^{\text {b: }}$ Yes & 22 & 18 & 18 & 64 & 0.967 & 3 & 0 & 0 & 100 & 0.643 & 3 & 0 & 67 & 33 & 0.059 \\
\hline No & 1512 & 11 & 28 & 61 & & 148 & 1 & 5 & 93 & & 393 & 3 & 17 & 80 & \\
\hline \multicolumn{16}{|l|}{ Country of birth } \\
\hline Australia & 1181 & 11 & 27 & 61 & 0.495 & 107 & 1 & 7 & 93 & 0.511 & 285 & 3 & 18 & 79 & 0.483 \\
\hline Other & 359 & 11 & 31 & 59 & & 45 & 2 & 2 & 96 & & 116 & 3 & 15 & 82 & \\
\hline \multicolumn{16}{|c|}{ Highest level education } \\
\hline School & 650 & 13 & 26 & 61 & 0.218 & 74 & 2.7 & 7 & 91 & 0.356 & 183 & 2 & 16 & 82 & 0.400 \\
\hline $\begin{array}{l}\text { Technical/trade } \\
\text { certificate }\end{array}$ & 341 & 9 & 35 & 57 & & 46 & 0 & 2 & 98 & & 126 & 6 & 17 & 77 & \\
\hline Tertiary & 535 & 10 & 27 & 64 & & 31 & 0 & 6 & 94 & & 89 & 2 & 19 & 79 & \\
\hline Other & 10 & 10 & 20 & 70 & & 0 & 0 & 0 & 0 & & 0 & 0 & 0 & 0 & \\
\hline \multicolumn{16}{|l|}{ Remoteness index } \\
\hline Metropolitan & 870 & 11 & 30 & 59 & 0.291 & 94 & 1 & 6 & 93 & 0.373 & 272 & 4 & 17 & 79 & 0.680 \\
\hline Inner regional & 345 & 12 & 24 & 64 & & 43 & 2 & 5 & 93 & & 98 & 3 & 18 & 79 & \\
\hline $\begin{array}{l}\text { Outer regional/ } \\
\text { Remote }\end{array}$ & 331 & 11 & 28 & 62 & & 16 & 0 & 0 & 100 & & 31 & 0 & 16 & 84 & \\
\hline \multicolumn{16}{|c|}{ SEIFA Relative Disadvantage ${ }^{c}$} \\
\hline $\begin{array}{l}\text { Quintile } 1 \text { most } \\
\text { disadvantaged }\end{array}$ & 217 & 15 & 29 & 57 & 0.287 & 3 & 0 & 0 & 100 & 0.928 & 39 & 5 & 23 & 72 & 0.618 \\
\hline Quintile 2 & 312 & 9 & 29 & 62 & & 20 & 0 & 5 & 95 & & 73 & 1 & 8 & 90 & \\
\hline Quintile 3 & 340 & 11 & 28 & 61 & & 42 & 2 & 5 & 93 & & 72 & 0 & 22 & 78 & \\
\hline Quintile 4 & 293 & 10 & 31 & 59 & & 33 & 3 & 6 & 91 & & 97 & 6 & 19 & 75 & \\
\hline
\end{tabular}


Table 3 Stated willingness to participate in health studies by demographic characteristics (Continued)

\begin{tabular}{|c|c|c|c|c|c|c|c|c|c|c|c|c|c|c|c|}
\hline $\begin{array}{l}\text { Quintile } 5 \text { least } \\
\text { disadvantaged }\end{array}$ & 384 & 12 & 25 & 64 & & 55 & 0 & 5 & 95 & & 120 & 3 & 17 & 80 & \\
\hline \multirow{2}{*}{$\begin{array}{l}\text { Previously done } \\
\text { health survey Yes } \\
\text { No }\end{array}$} & 384 & 6 & 21 & 73 & $<0.001$ & 153 & 1 & 5 & 94 & - & 401 & 3 & 17 & 80 & - \\
\hline & 1107 & 13 & 30 & 57 & & 0 & 0 & 0 & 0 & & 0 & 0 & 0 & 0 & \\
\hline $\begin{array}{l}\text { Previously refused } \\
\text { health survey Yes }\end{array}$ & 166 & 19 & 33 & 48 & $<0.001$ & 11 & 0 & 9 & 91 & 0.585 & 38 & 5 & 18 & 76 & 0.501 \\
\hline No refusal & 1329 & 10 & 27 & 63 & & 135 & 0 & 5 & 95 & & 355 & 3 & 17 & 81 & \\
\hline \multirow[t]{2}{*}{$\begin{array}{l}\text { Long-term disease/ } \\
\text { disability Yes }\end{array}$} & 481 & 9 & 23 & 68 & 0.002 & 65 & 2 & 2 & 97 & 0.131 & 115 & 4 & 16 & 80 & 0.967 \\
\hline & 1150 & 12 & 30 & 59 & & 85 & 1 & 8 & 91 & & 278 & 3 & 18 & 80 & \\
\hline $\begin{array}{l}\text { Spontaneously } \\
\text { raised privacy/ } \\
\text { health issue during } \\
\text { interview Yes }\end{array}$ & 19 & 26 & 21 & 53 & 0.245 & 2 & 0 & 0 & 100 & 0.708 & 5 & 20 & 40 & 40 & 0.021 \\
\hline No & 1527 & 11 & 29 & 61 & & 151 & 1 & 5 & 93 & & 396 & 3 & 17 & 80 & \\
\hline
\end{tabular}

${ }^{\mathrm{a} A}$ chi squared test for trend was used for comparing the numbers for all variables except age, Remoteness index and SEIFA for which ordinal logistic regression was used

${ }^{\mathrm{b}} \mathrm{ATS} /$ is the acronym for Aboriginal and Torres Strait Islander

CSEIFA Socio-Economic Indexes for Areas is an aggregate score of relative socio-economic disadvantage; the lower the score the higher the relative disadvantage 
who were unwilling to participate were more likely to raise privacy spontaneously during the interview $(p=0.021)$ although numbers were small (1.3\%).

The multivariable analyses revealed very little difference in the importance of any predictor. Exceptions were for the general population group where long term disability was no longer significant due to adjustment for age $(p=0.13)$, and for the cohort population raising privacy issues which did not retain its statistical significance $(p=0.06)$. In the case control study there were too few participants reporting lack of willingness to participate in order to perform a reliable multivariable analysis.

Factors which increased participants' stated willingness to participate in health surveys (Fig. 1) were: research to treat or prevent a disease or to better plan hospital services; research about a disease they or a close family member or friend had experienced; government or charity funded research; receipt of a summary of the results.

With respect to mode of contact, people were more willing to have their name provided to researchers by their GP when diagnosed with a particular disease, than to have their name taken from the electoral roll, the telephone directory or have their telephone number randomly generated.

The majority of participants in each age and sex group expressed preference for an in-depth 4-page over a brief 1page study explanation (Table 4). Both men and women, particularly younger people, expressed a preference for an online survey over a telephone survey. Older people, particularly women, preferred a mail survey. A telephone survey was the least preferred method for all subgroups except those over 60 years who least favoured an online survey.

\section{Discussion}

Overall, the majority (61\%) of participants in our study were willing to participate in health research and only about $11 \%$ said that they were unwilling.

Participation in our study was higher for those who had previously participated in health research across two methodologies, a case-control or cohort health study, than for the general population sample. This high rate of participation by people recruited from our previous studies suggests that their participation in a health study had not diminished their willingness to participate. In the case of the largely male cohort, the responders continued to be willing to take part in research, although men usually show lower interest in participating in health research than women, as seen among the general population participants in this study. Case-control participants had a higher participation rate in this survey than the cohort participants which may be a result of the shorter time between the case-control study and our survey. It may also reflect the reduced interest in participating in a study which is less personally relevant than the cohort study. There may be value in ensuring that all study participants are canvassed at set up as to their willingness to participant in future studies, as was done in the WABoHS study, and these individuals may provide a pool for future study recruitment.

A greater proportion of the case-control study participants (43\%) had a long term disease or disability than did the general population sample $(25 \%)$ or the cohort study population (30 \%) but an individual's case-control status was unknown in this study. Those who were cases may have been motivated by their experience of a serious disease.

Some questions such as education level or long term disability may have been subject to reporting bias but the remoteness index and SEIFA were coded from area measures and are not likely to be biased.

A limitation of our study was the $44.5 \%$ participation rate for the general population sample. Those who refused to take part in our study may also be unwilling to take part in other health research and/or might have taken part if it had not been a telephone survey. Response rates may have decreased in bona fide health research because of confusion with increased telemarketing 'surveys' or because of reduced volunteering more generally in society [4]. An

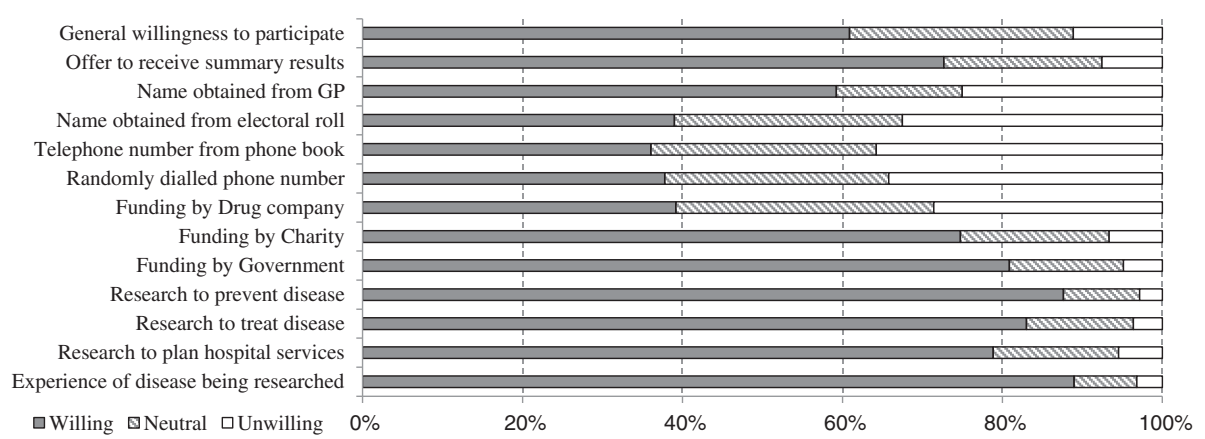

Fig. 1 Percent of the general population participants who were willing to take part in health research, by whether they would receive a summary of results, by how their name/phone number had been identified (4 options), by method of study funding ( 3 options), by reason for the research ( 3 options) and by whether the person had direct experience/knowledge of the disease being investigated 
Table 4 Australian general population sample preference for study explanation, and survey method by sex and age group ( $\%$ by column)

\begin{tabular}{|c|c|c|c|c|c|c|}
\hline & Total & Men & Women & $<40$ years & $40-60$ years & $>60$ years \\
\hline & $n(\%)$ & $n(\%)$ & $n(\%)$ & $n(\%)$ & $n(\%)$ & $n(\%)$ \\
\hline \multicolumn{7}{|l|}{ Study explanation } \\
\hline 1-page explanation & $631(42)$ & $276(43)$ & $355(40)$ & $182(43)$ & 244 (39) & $200(43)$ \\
\hline 4-page explanation & $838(55)$ & $339(53)$ & $499(57)$ & $230(54)$ & 367 (59) & $240(52)$ \\
\hline \multirow[t]{2}{*}{ Don't know/care } & $51(3)$ & $24(4)$ & $27(3)$ & $11(3)$ & $15(2)$ & $25(5)$ \\
\hline & & \multicolumn{2}{|l|}{$P^{a}=0.343$} & \multicolumn{2}{|l|}{$P^{a}=0.018$} & \\
\hline \multicolumn{7}{|l|}{ Survey method } \\
\hline Telephone survey & $310(20)$ & $140(22)$ & $170(19)$ & $70(16)$ & $118(19)$ & $122(26)$ \\
\hline Mail survey & $498(32)$ & $182(28)$ & $316(35)$ & $79(18)$ & $193(30)$ & $225(47)$ \\
\hline Online survey & $623(40)$ & $284(44)$ & $339(38)$ & $256(60)$ & $277(44)$ & $87(18)$ \\
\hline \multirow[t]{2}{*}{ Don't know/care } & $111(7)$ & $43(7)$ & $68(8)$ & $23(5)$ & $48(8)$ & $40(8)$ \\
\hline & & \multicolumn{2}{|l|}{$P^{a}=0.011$} & \multicolumn{2}{|l|}{$P^{\mathrm{a}}<0.001$} & \\
\hline
\end{tabular}

${ }^{a}$ Chi squared

investigation of public opinion in Canada published in 2010 included 3000 participants selected from the telephone directory with $58.3 \%$ participation of those eligible, while Molster et al. (2007) [18] obtained a $78 \%$ response rate from 600 participants in a study of the views of Western Australians on the collection of identifiable data [26].

This form of research clearly involves some circularity, in that those who took part are de facto, willing to participate. However, it is difficult to see how we can explore people's views without asking them and there were informative differences in rates of willingness associated with different questions and different subgroups of participants. Interviewees were advised about the overall aims of the study before giving consent to participate and it may be that the particular topic might have induced them to participate when ordinarily they would not have agreed. Researchers have suggested that factual willingness to participate in health research is greater than hypothetical willingness. That is, a higher proportion of people actually take part in research when asked than say they are willing do so in answer to a hypothetical question [27]. In support of this, $11 \%$ of the general population sample who took part in our survey said they were unwilling or very unwilling to take part in health research.

We have no information about the individuals who did not answer the telephone or who answered but did not take part in the study. The telephone numbers were obtained from a commercial list without such information as age or sex. In view of this we cannot assess any non-response bias. We have compared the demographic descriptors of our general population sample to those of the general population to assess how different they are to the general population however. Our general population survey respondents were more likely to be female and older than the Australian population. Participation differed with measures of socioeconomic disadvantage and by individual level educational attainment. These demographic differences in participation have been found in other studies [12, 28-32].

We found a very modest increase in response when personalised letters were sent before the telephone survey to those for whom an address was available. We did not randomise for those with and without an address and these groups may differ in regards to willingness to respond. Randomisation would have enabled us to assess whether receiving a letter enhanced participation in our study. This is consistent with a systematic review [33] and subsequent study [34] which found that personalised questionnaires and letters increased the response for postal questionnaires. However, a recent randomised controlled trial in Australia, showed that letters did not increase the participation rate in an epidemiological study using telephone interviews [35].

People were most likely express willingness to participate if the research was about treating or preventing a disease, or if it was about a disease that they or a family member or friend had experienced. Expressed willingness was increased when the question provided more information about the reason for the study, (hospital planning, treatment or prevention of a disease) or about the source of the funding, (government or charity) or if the participants were to receive a copy of the results. These findings seem to indicate that people are more prepared to take part in studies where the reason for the research is evident and the findings will be made available.

Australians in our study were less likely to be willing to participate in research sponsored by a pharmaceutical company than by a university or charity. Willison et al,, in a survey of Canadian general practice patients, also found concern about their records being used for research by drug companies [36]. Canadians were also less 
willing to take part in research sponsored by other private sources such as a private research firm [18] or a private insurance company [36]. In a systematic review of randomised controlled trials of postal questionnaires, those originating from universities were about $30 \%$ more likely to be completed and returned than were questionnaires from other sources [33].

Many of our participants, like those surveyed in Canada [18], wanted a copy of the summary results from the research. Kaufman et al. [37] found reduced willingness to participate if respondents were told that they would not receive their individual research results and their reduced willingness was related to privacy concerns. Very few of our participants raised concerns about privacy during the interview.

Difficulty in identifying and contacting potential participants is a barrier to participation. We used randomly selected telephone numbers for all the general population participants, but fewer than $40 \%$ of these participants indicated that this would be a contact methodology that would make them favour participation (Fig. 1).

Our study asked participants about their preferences for survey delivery, i.e., online or mail and we found that younger participants expressed a preference for online surveys but this has not always been successful strategy for recruitment in practice [4]. A recent web-based survey of mental health among Australian University students had a $25 \%$ participation rate [38]. Newer survey methods such as web based questionnaires have advantages and disadvantages in comparison with traditional survey methods such as telephone or postal questionnaires but have been used considerably less commonly in comparison and there are concerns about nonresponse bias and reliability of the data collected by this method [39]. Our study has provided contemporary information using an established method to inform future recruitment to health research studies.

Finally, the preference in every group for an in-depth 4-page over a brief 1-page study explanation came as a surprise, given the concern often expressed over the lengthy, potentially confusing information that is often required to be provided to participants. If the contrast had been between 1,4 , and 12 pages, the implications of this finding might have been clearer.

Reduced participation over time has been encountered across all epidemiological study designs, in terms of non-response as well as refusal, and a low response rate may reduce the statistical power and generalisability of results to the wider community. Therefore it is important to maintain current understanding of people's willingness to participate in health research and factors that affect their willingness to participate.
Despite declining participation rates, the fact that participation in health research studies is seen positively is a good sign. Our findings have several implications for future research with a view to improving participation in health research studies. We suggest that the bone fide credentials of health researchers or their institutions are identified early in the interview process to distinguish them from telemarketing 'surveys'. Further that the reason for the call is communicated clearly and is understandable to participants. The source of funding should be identified, and if the funding source is not a profit-making entity this should be emphasised. Participants should be made aware of the ways that the findings will be made available. Participants should be offered a range of methods of data collection (where feasible) eg offering the options of telephone, postal and web based survey. Different demographic groups may need to be targeted with different recruitment methodologies. A one page summary plain language statement should be provided alongside a longer (4-5 page) explanation for those who wished to have more information. Some individuals may have been motivated to participate by their knowledge of a serious disease or disability. Information materials should adequately describe, in lay terms the nature of the disease and the implications for sufferers of the disease. This may be particularly important for controls. Finally, researchers should ask participants at the time of enrolment to studies to agree to be contacted for future surveys.

\section{Conclusions}

The majority of respondents to this survey indicated that they were willing or very willing to participate in health research. The experience of previous participation in epidemiological surveys did not reduce willingness to participate, indeed there was a much higher response rate among previous participants in a cohort and a case control study.

Participation rates in telephone surveys have fallen over time. Our survey only included those willing to take part in a survey, but it is encouraging that those who have already taken part in health research are highly responsive and very willing to take part in another study. Our study could also inform practice to improve participation in epidemiological health research and participants' experience of their participation.

\section{Abbreviations}

ABS: Australian Bureau of Statistics; ATSI: Aboriginal and Torres Strait Islander; CATI: Computer-assisted telephone interview; GP: General practitioner; SEIFA: Socio-economic indexes for areas.

\section{Competing interests}

The authors declare that they no competing interests. 


\section{Authors' contributions}

$D G, H K, B L, D Z$, LF designed the study. DG, HK, BL, DZ, LF CS prepared the survey questionnaire. $C S$ and $B L$ carried out qualitative research that informed the questionnaire. AF assisted with the statistical analyses. All authors have discussed the findings, read, revised and agreed to the final manuscript. All authors read and approved the final manuscript.

\section{Authors' information}

Not applicable.

\section{Acknowledgements}

This work was supported by a grant from the National Health and Medical Research Council (NHMRC), Australia, grant number 545957, years 2009-2012. Lin Fritschi is supported by fellowships from the NHMRC and Cancer Council Western Australia.

Ngaire Brown conducted the interviews with the Aboriginal and Torres Strait Islander focus groups. The Social Research Centre North Melbourne conducted the telephone survey.

\section{Author details}

${ }^{1}$ Department of Epidemiology and Preventive Medicine, Monash University, The Alfred Centre, 99 Commercial Rd, Melbourne 3004, VIC, Australia. ${ }^{2}$ VU Human Research Ethics Committee, Office For Research, FP, Victoria University, PO Box 14428, Melbourne, VIC 8001, Australia. ${ }^{3}$ S'chool of Public Health, Curtin University, Kent Street, Bentley, WA 6102, Australia.

Received: 11 December 2014 Accepted: 24 September 2015 Published online: 05 October 2015

\section{References}

1. Morton LM, Cahill J, Hartge P. Reporting participation in epidemiologic studies: A survey of practice. Am J Epidemiol. 2005;163(3):197-203.

2. Jones J. The effects of non-response on statistical inference. J Health Soc Policy. 1996:8:49-62

3. Kjoller M, Thoning H. Characteristics of nonresponse in the Danish Health Interview Surveys, 1987-1994. Eur J Public Health. 2005:15:528-35.

4. Galea S, Tracey M. Participation rates in epidemiologic studies. Ann Epidemol. 2007;17:643-53.

5. OToole J, Sinclair M, Leder K. Maximising response rates in household telephone surveys. MBMC Med Res Methodology. 2008;8:71-5.

6. Boyle T, Landrigan J, Bulsara C, Fritschi L, Heyworth J. Increasing study participation. Epidemiology. 2011;22(2):279.

7. Curtin R, Presser $\mathrm{S}$, Singer E. Changes in telephone survey nonresponse ove the past quarter century. Pub Op Quart. 2005;69(1):87-98.

8. Harris MA, Levy AR, Teschke KE. Personal privacy and public health: potential impacts of privacy legislation on health research in Canada. Can J Pub Health. 2008:99(4):293-6.

9. Madigan MP, Troisi R, Potischman N, Brogan D, Gammon MD, Malone $\mathrm{KE}$, et al. Characteristics of respondents and non-respondents from a case-control study of breast cancer in younger women. Int J Epidemiol. 2000;29(5):793-8.

10. Kho ME, Duffett M, Willison DJ, Cook DJ, Brouwers MC. Written informed consent and selection bias in observational studies using medical records: systematic review. BMJ. 2009;338:b866.

11. Kypri K, Samaranayaka A, Connor J, Langley J, Maclennan B. Non-response bias in a web-based health behaviour survey of New Zealand tertiary students. Prev Med. 2011;53(4-5):274-7.

12. Maclennan B, Kypri K, Langley J, Room R. Non-response bias in a community survey of drinking, alcohol-related experiences and public opinion on alcohol policy. Drug Alcohol Depend. 2012;126(1-2):189-94

13. Fritschi L, Kelsall H, Loff B, Slegers C, Zion D, Glass D. A cross-sectional survey to investigate community understanding of medical research ethics committees. J Med Ethics. 2015;41:545-8.

14. Glass DC, Gray CN, Jolley DJ, Gibbons C, Sim MR, Fritschi L, et al. Leukemia risk associated with low level benzene exposure. Epidemiology. 2003:15(5):569-77.

15. Glass DC, Wood E, Del Monaco A, Sim M. Cohort Profile: Health Watch-a 30-year prospective cohort study of Australian 5 petroleum industry workers. Int J Epidem. 2015.
16. lacopetta B, Heyworth J, Girschik J, Grieu F, Clayforth C, Fritschi L. The MTHFR C677T and $\triangle$ DNMT3B C-149 T polymorphisms confer different risks for right- and left-sided colorectal cancer. Int J Cancer. 2009:125(1):84-90

17. Boyle T, Fritschi L, Platell C, Heyworth J. Lifestyle factors associated with survival after colorectal cancer diagnosis. Br J Cancer [Epidemiology] 2013;109(3):814-22.

18. Teschke K, Marino S, Chu R, Tsui J, Harris MA, Marion S. Public opinions about participating in health research. Can J Pub Health. 2010;101(2):159-64.

19. Slegers C, Zion D, Glass D, Kelsall H, Fritschi L, Brown N, et al. Why do people participate in epidemiological research? J Bioethical Inquiry. 2015. doi:10.1007/s11673-015-9611-2.

20. Australian Bureau of Statistics. 2039.0 - Information Paper: An Introduction to Socio-Economic Indexes for Areas (SEIFA), 2006. Canberra: Australian Bureau of Statistics; 2012. http://www.abs.gov.au/ ausstats/abs@.nsf/mf/2039.0/.

21. Australian Bureau of Statistics. 1216.0 - Australian Standard Geographical Classification (ASGC) - Electronic Publication, 2005. Canberra: Australian Bureau of Statistics; 2012. http://www.abs.gov.au/Ausstats/abs@.nsf/0/ 0D204FD3DCD90564CA256F19001303A2?open

22. Australian Bureau of Statistics. 4102.0 Australian Social Trends, Data Cube Canberra: Australian Bureau of Statistics; 2008. http://www.abs.gov.au/ AUSSTATS/abs@.nsf/DetailsPage/4102.02008?OpenDocument.

23. Australian Bureau of Statistics. 3105.0.65.001 Australian Historical Population Statistics, September 2011. Canberra: Australian Bureau of Statistics; 2012. http://www.abs.gov.au/AUSSTATS/abs@.nsf/allprimarymainfeatures/ E9D41DAAF0D8157ACA257A2200120EF2?opendocument.

24. Australian Bureau of Statistics. 4102.0 Australian Social Trends, Data Cube Population 1998-2011. Canberra: Australian Bureau of Statistics; 2012. http://www.abs.gov.au/AUSSTATS/abs@.nsf/allprimarymainfeatures/ E9D41DAAF0D8157ACA257A2200120EF2?opendocument.

25. StataCorp. Stata Statistical Software: Release 11.2. Version. 10th ed. Texas: StataCorp LP; 2011

26. Molster C, Bower C, O'Leary P. Community attitudes to the collection and use of identifiable data for health research - is it an invasion of privacy? Aust NZ J Pub Health. 2007:31:313-7.

27. Johnsson L, Helgesson G, Rafnar T, Halldorsdottir I, Chia K-S, Eriksson S, et al. Hypothetical and factual willingness to participate in biobank research. Eur J Hum Genetics. 2010;18(11):1261-4.

28. Angus V, Entwistle V, Emslie M, Walker $\mathrm{K}$, Andrew J. The requirement for prior consent to participate on survey response rates: A population-based survey in Grampian. BMC Health Serv Res. 2003;3:21-32.

29. Sogaard A, Selmer R, Bjertness E, Thelle D. The Oslo Health Study: The impact of self-selection in a large, population-based survey. Int J Equity Health. 2004:3:3-15.

30. van der Waerden JEB, Hoefnagels C, Jansen MWJ, Hosman CMH. Exploring recruitment, willingness to participate, and retention of low-SES women in stress and depression prevention. BMC Public Health. 2010;10:588-94.

31. Shickle D, Carlisle J, Wallace S, Cork M, Beyleveld D, Bowns I, et al. Patient Electronic Record: Information and Consent (PERIC) Public attitudes to protection and use of personal health information. Sheffield: School of Health and Related Research, University of Sheffield; 2002.

32. Iversen A, Liddell K, Fear N, Hotopf M, Wessely S. Consent, confidentiality, and the Data Protection Act. BMJ. 2006:332(7534):165-9.

33. Edwards P, Roberts I, Clarke M, DiGuiseppi C, Pratap S, Wentz R, et al. Methods to increase response rates to postal questionnaires.[see comment]. Cochrane Database Syst Rev. 2007;2, MR000008.

34. Edwards S, Slattery M, Edwards A, Sweeney C, Murtaugh M, Palmer L, et al. Factors associated with response to a follow-up postal questionnaire in a cohort of American Indians. Prev Med. 2009;48(6):596-9.

35. Carey R, Glass DC, Reid A, Benke G, Fritschi L. An advance letter did not increase response rates in a telephone survey: A randomised trial. J Clin Epidemiol. 2013;71:55-62.

36. Willison DJ, Keshavjee K, Nair K, Goldsmith C, Anne M. Holbrook for the COMPETE investigators. Patient consent preferences for research uses of information in electronic medical records: interview and survey data. BMJ. 2003:326:326-73.

37. Kaufman DJ, Murphy-Bollinger J, Scott J, Hudson KL. Public opinion about the importance of privacy in biobank research. Am J Hum Genetics. 2009;85(5):643-54 
38. Said D, Kypri K, Bowman J. Risk factors for mental disorder among university students in Australia: findings from a web-based cross-sectional survey. Soc Psychiatry Psychiatr Epidemiol. 2013;48(6):935-44.

39. van Gelder MMHJ, Bretveld RW, Roeleveld N. Abstracts of the 3rd North American Congress of Epidemiology, June 21-24, 2011 Montreal, Canada Web-based Questionnaires: The Future in Epidemiology? Am J Epidemiol. 2011;173(11):S1-S316.

Submit your next manuscript to BioMed Central and take full advantage of:

- Convenient online submission

- Thorough peer review

- No space constraints or color figure charges

- Immediate publication on acceptance

- Inclusion in PubMed, CAS, Scopus and Google Scholar

- Research which is freely available for redistribution 